\title{
Tracking the Autumn Migration of the Bar-Headed Goose (Anser indicus) with Satellite Telemetry and Relationship to Environmental Conditions
}

\author{
Yaonan Zhang, ${ }^{1}$ Meiyu Hao, ${ }^{1,2}$ John Y. Takekawa, ${ }^{3}$ Fumin Lei, ${ }^{4}$ Baoping Yan, ${ }^{2}$ \\ Diann J. Prosser, ${ }^{5}$ David C. Douglas, ${ }^{6}$ Zhi Xing, ${ }^{7}$ and Scott H. Newman ${ }^{8}$ \\ ${ }^{1}$ Cold and Arid Regions Environmental and Engineering Research Institute, Chinese Academy of Sciences, Lanzhou 730000, China \\ ${ }^{2}$ Computer Network Information Center, Chinese Academy of Sciences, Beijing 100190, China \\ ${ }^{3}$ US Geological Survey, Western Ecological Research Center, Vallejo, CA 94592, USA \\ ${ }^{4}$ Institute of Zoology, Chinese Academy of Sciences, Beijing 100101, China \\ ${ }^{5}$ US Geological Survey, Patuxent Wildlife Research Center, Beltsville, MD 20705, USA \\ ${ }^{6}$ US Geological Survey, Alaska Science Center, Juneau, AK 99801, USA \\ ${ }^{7}$ State Forestry Administration, Qinghai Lake National Nature Reserve, Xining 810000, China \\ ${ }^{8}$ EMPRES Animal Health, Wildlife Health \& Ecology Unit, Animal Production and Health Division, Food \& Agriculture Organisation \\ of the United Nations, 00153 Rome, Italy
}

Correspondence should be addressed to Yaonan Zhang, yaonan@lzb.ac.cn

Received 11 April 2011; Accepted 27 July 2011

Academic Editor: Stephen Reid

Copyright () 2011 Yaonan Zhang et al. This is an open access article distributed under the Creative Commons Attribution License, which permits unrestricted use, distribution, and reproduction in any medium, provided the original work is properly cited.

\begin{abstract}
The autumn migration routes of bar-headed geese captured before the 2008 breeding season at Qinghai Lake, China, were documented using satellite tracking data. To assess how the migration strategies of bar-headed geese are influenced by environmental conditions, the relationship between migratory routes, temperatures, and vegetation coverage at stopovers sites estimated with the Normalized Difference Vegetation Index (NDVI) were analyzed. Our results showed that there were four typical migration routes in autumn with variation in timing among individuals in start and end times and in total migration and stopover duration. The observed variation may be related to habitat type and other environmental conditions along the routes. On average, these birds traveled about 1300 to $1500 \mathrm{~km}$, refueled at three to six stopover sites and migrated for 73 to 83 days. The majority of the habitat types at stopover sites were lake, marsh, and shoal wetlands, with use of some mountainous regions, and farmland areas.
\end{abstract}

\section{Introduction}

A migratory bird species is defined by its seasonal movements between breeding and wintering grounds. China is home to a large number of migratory bird species that follow three major flyways dividing eastern, central, and western regions of the country. Recent research $[1,2]$ has indicated that there may be a relationship between avian migration and the spread of the highly pathogenic avian influenza (HPAI) H5N1, especially in central China along the Central Asian Flyway [3]. Along the migration routes, birds do not fly continuously, but instead, stopover to feed and rest at refueling sites. During these stopover periods, any viruses carried by birds may be transmitted to other migratory hosts that could act as carriers of HPAI, with potential for transmission to domestic chickens and possibly humans [4]. Therefore, analysis of the environmental conditions along these routes is critical to improve understanding of the migration strategies of birds that may be acting as carriers.

The bar-headed goose (Anser indicus) is distributed throughout India, Bangladesh, Mongolia, and areas of west and central China. Many bar-headed geese fly over the Himalayas during migration between Tibet and India [5], and bar-headed geese that breed in Qinghai Lake may spend the winter in Tibet [6] or other areas (central and northeast India or Ladakh: [7]. The first satellite tracking of bar-headed 
geese was conducted in India in 1999-2000, and it served as a hypothesis-generating exercise to further examine the ecology of this species $[8,9]$. In central China, the migration routes from Qinghai Lake to Tibet were not documented until very recently [3], and detailed information on the routes and important stopovers has not been previously available.

Traditional methods to study bird migration such as ringing and recovery are straightforward to carry out, but they are time consuming with a low rate of data recovery, especially in the remote regions of Asia. There was no useful field data about bird migration from Qinghai Lake prior to 2004 , even with availability of advanced tracking technologies [10]. In 2005, the global spread of HPAI H5N1 included an outbreak where thousands of bar-headed geese and other birds died at Qinghai Lake, China. This was the first known case of such a large number of migratory bird deaths caused by HPAI H5N1, and it aroused great attention both in China and abroad. For that reason, the Chinese Ministry of Science and Technology (MOST) initiated several emergency projects, one of which was to track bird migration with satellite telemetry [11].

The movements and habitat utilization of breeding barheaded geese at Qinghai Lake were documented through radiotracking and collar marking by Liu et al. [12]. The movements of four species of breeding water birds-barheaded geese (Anser indicus), brown-headed gulls (Larusbrunnicephalus), great black-headed gulls (L. ichthyaetus), and great cormorants (Phalacrocorax carbo)-were studied using collar marking, radio and satellite tracking at Qinghai Lake between April and September 2006 [13]. Tang et al. [14] converted these biological data into computational analyses and developed efficient algorithms for data analysis. Their key contribution included applying concepts of hierarchical clustering to identify migration habitats and contributed to correlating movements to HPAI H5N1 outbreaks in wild birds and poultry [3].

Prior to these studies, Song et al. [6] had conducted research in 1991 and 1992 investigating population numbers and wintering habitats, and discovered that the watersheds of the Yarlung Zangbo River, the Lhasa River, and the Nianchu River were major wintering sites for bar-headed geese. They estimated 10,000 bar-headed geese wintered at sites in these areas including river, farmland, and marshland habitats but more recent counts indicate that the total wintering population has grown to $>30,000$ wintering geese [15]. Since this research was limited to studying geese at their breeding and wintering grounds, stopover sites and migratory routes used by the geese were not documented.

In this paper, we present information on bar-headed goose migration routes, stopover sites, and the relationship to environmental conditions from satellite-tracking data. Do birds marked with satellite transmitters follow similar routes? Do geese use one or more stopover areas during their migration? Do selected stopover sites vary with surface temperature and the Normalized Difference Vegetation Index (NDVI)? We provide time series monitoring data of green-up and isothermal diagrams interpolated from monthly mean temperatures obtained from meteorological observatories.
The U. S. Geological Survey (USGS), United Nations Food and Agriculture Organization (FAO), and the Chinese Academy of Science (CAS) collaborated to carry out a project on satellite-marking bar-headed geese. Satellite transmitters or Platform-Transmitting Terminals (PTTs) were attached to bar-headed geese captured at Qinghai Lake, and satellite signals were received and processed through the ARGOS Location System. This system provided data every two hours, including ID number, latitude and longitude, time stamp, and location class. Location classes varied from one area to another, and different classes provided different levels of precision. Locations were divided into seven classes of decreasing accuracy: 3, 2, 1, 0, A, B, and Z. Location classes, $3,2,1$, and 0 were assigned an error radius of $\leq 150 \mathrm{~m}, 150$ $350 \mathrm{~m}, 350-1000 \mathrm{~m}$, and $>1000 \mathrm{~m}$, respectively. Auxiliary location classes $\mathrm{A}, \mathrm{B}$, and $\mathrm{Z}$ are deemed less reliable and are not assigned accuracy estimates.

\section{Methods}

2.1. Acquisition of Satellite-Tracking Data. Since geese were tracked by several satellites during the course of each day, the duration and strength of a given satellite signal was often insufficient to provide a location. To compensate for this deficiency and ensure better accuracy, the highest location class during a day was reported. Eleven bar-headed geese (numbers 82086, 67695, 82079, 82084, 82080, 82085, 82082, $82081,82076,74901,74902)$ with continuous tracking data available through the autumn migration were selected for the analysis. They were tracked on their 2008 autumn migration from Qinghai Lake to their wintering grounds, and their migration was compared to other birds such as red-crowned cranes (Grus japonensis) [16] and Honey-buzzards (Pernis apivorus) [17].

2.2. Migration Routes in China and Stopover Duration. Qinghai Lake, located in the northeastern part of Qinghai province, is the largest salt-water lake in China and the largest known breeding colony for bar-headed geese [18]. The main wintering sites for the geese are the watersheds of the Yarlung Zangbo River, the Lhasa River, and the Nianchu River in Tibet where there is moving water during the winter in the river, with available farmland and marshland habitats. Every year from March to April, bar-headed geese return from their wintering grounds to the breeding grounds at Qinghai Lake, and from September to November, reverse their journey, traveling on their autumn migration from breeding grounds to wintering grounds. Bar-headed goose migratory stopover sites along these routes were determined by analyzing both satellite-tracking data and field data.

We used ArcGIS9.3 (Environmental Systems Research Institute, Inc., Redlands, California, USA) to plot and analyze telemetry locations. The analysis of duration time was based on four bar-headed geese with complete migration tracks. The route and stopovers were approximately the same for each bar-headed goose. We concluded that seven of the geese bred and moulted in Qinghai Lake, since they stayed in the area for a similar period to other successfully breeding 
TABle 1: Vegetation types in bar-headed goose home range around Qinghai Lake, China. Data was provided by the Computer Network Information Center, Chinese Academy of Sciences and vegetation types identified by the Qinghai Lake National Nature Reserve.

\begin{tabular}{|c|c|c|}
\hline Vegetation types & Community & Distributed sites \\
\hline \multirow{5}{*}{ Steppe } & Stipa krylovii & Upper Lucidao, Dandao \\
\hline & Allium przewalskianum & Haixinshan, Dandao \\
\hline & Leymus spp. & Niaodao \\
\hline & Leymus spp., Alkaligrass & North of Buhahe Delta \\
\hline & Artemisiia annua linn & Sankuaishi \\
\hline Desert steppe & Stipa breviflora & Gazihe, Haixinshan \\
\hline \multirow{10}{*}{ Swamp meadow } & Blysmus sinocompressus & Garila, Heimahe, \\
\hline & Dlysmus stnocompressus & Gazihe wetland \\
\hline & Blysmus sinocompressus, & Daotanghe wetland \\
\hline & Blysmus sinocompressus & Qinghaihunongchang \\
\hline & Blysmus sinocompressus, & Dandao \\
\hline & Blysmus sinocompressus, & East of Shadao \\
\hline & Polygonum sibiricum, Glaux & Lower Lucidao \\
\hline & Alkaligrass & Shenhekou \\
\hline & $\begin{array}{l}\text { Alkaligrass, Polygonum } \\
\text { sibiricum }\end{array}$ & Quanwan wetland \\
\hline & Polygonum sibiricum, Glaux & Tiebuqiahekou \\
\hline \multirow{6}{*}{ Saline meadow } & Kobresia graminifolia & Xiaohupo \\
\hline & Eleocharis valleculosa & Hadatan \\
\hline & $\begin{array}{l}\text { Leymus spp., Potentilla } \\
\text { anserine }\end{array}$ & Qaunjihekou \\
\hline & Alkaligrass, Glaux maritima & Shaliuhekou \\
\hline & $\begin{array}{l}\text { Alkaligrass, Glaux } \\
\text { maritime, sedge }\end{array}$ & Shadao \\
\hline & Polygonum sibiricum & Shaliuhekou 2 \\
\hline Alpine meadow & Kobresia pygmaea, Kobresia & Village of Garila \\
\hline Shrubs & Myricaria squamosa & Buhahe, Shaliuhe \\
\hline Abandoned cropland & $\begin{array}{l}\text { Snowmastiff, Wildrye } \\
\text { Leymus spp. }\end{array}$ & Qinghaihunongchang \\
\hline
\end{tabular}

geese (see [19]). They then traveled via Donggeicuona Lake, Alake Lake, Qumalai, Hangcuo, and others, and wintered in the watersheds of the Yarlung Zangbo and Nianchu rivers in Tibet. Two geese went to Qinghai Lake for a short stay and then bred and moulted in the wetlands near Hala Lake, traveled by way of Alake Lake, Qumalai, and others, and wintered in the watershed of the Yarlung Zangbo River in Tibet. One bar-headed goose bred and moulted in Qinghai Lake, then traveled by way of Donggeicuona Lake, Eling Lake, and Hangcuo for a short stay in Tibet, then flew over the Himalayan Mountains to winter in India. One bar-headed goose bred at Qinghai Lake (on the basis of its length of stay), moulted at either Eling Lake or Zhaling Lake (its signal was lost after November 25th, but it was found there again the following year), and likely migrated south to a different area for the winter.
2.3. Vegetation at Breeding and Stopover Sites. Qinghai Lake is a major breeding and stopover site for many migratory birds. The lake is about 3100 meters above sea level with an area of $4277 \mathrm{~km}^{2}$. The unique vegetation distribution pattern around Qinghai Lake is a result of the geologic structures, geomorphologic features, and climatic environment near Plateau Lake. Several types of vegetation are found in the barheaded goose's home range around Qinghai Lake (Table 1) including dominant species of grasses that may be used as foraging resources (CNIC, unpublished data). Bar-headed geese are distributed mainly in the areas around Qinghai Lake in the Qinghai Lake National Nature Reserve with larger numbers in the area northwest of the lake and smaller numbers to the southeast (Figure 2). The area frequented by the geese was mainly swamp meadows, saline meadows, 
$80^{\circ} 0^{\prime} 0^{\prime \prime} \mathrm{E}$

$85^{\circ} 0^{\prime} 0^{\prime \prime} \mathrm{E}$

$90^{\circ} 0^{\prime} 0^{\prime \prime} \mathrm{E}$

$95^{\circ} 0^{\prime} 0^{\prime \prime} \mathrm{E}$

$100^{\circ} 0^{\prime} 0^{\prime \prime} \mathrm{E}$

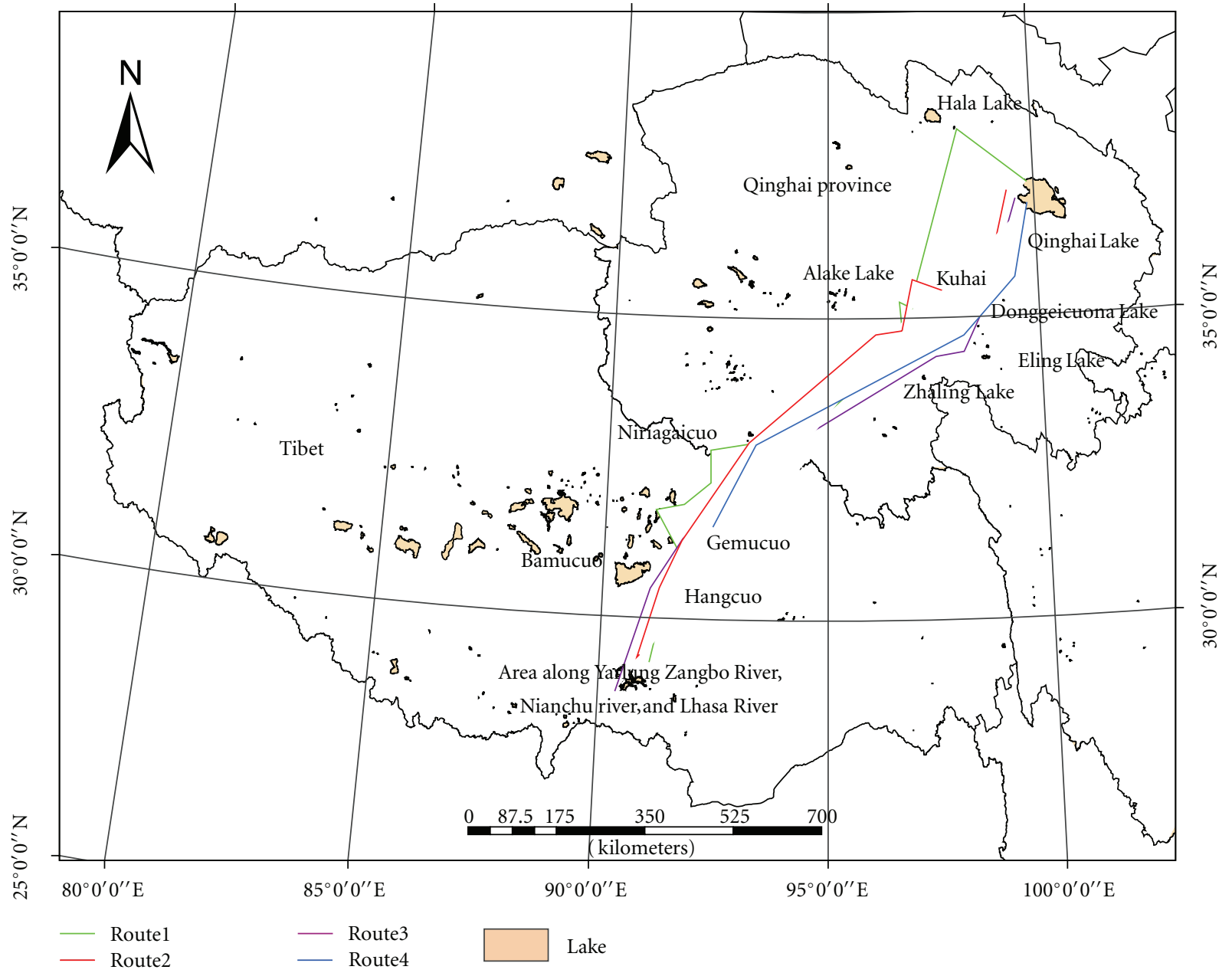

FIGURE 1: Bar-headed goose migratory routes and stopover duration of 4 representative geese from breeding to wintering sites.

steppes, and desert as well as alpine meadows, shrubland, and abandoned farmland.

2.4. Stopover Sites and Temperature Variation. Temperature change is an important cue for bar-headed geese to migrate. Comparing the changes in mean interannual temperature fluctuations during the winter every ten years, the seasonal changes of the climate on the Tibetan Plateau is gradually moving from north to south. However during the winter, the temperatures are still warmer in the south and colder in the north, although elevation, latitude and terrain also influence the local temperatures [20]. The current study used anisothermal diagram based on monthly mean temperatures interpolated from meteorological observatories to map the variation in temperatures at stopover areas during the autumn (Figure 3). The mean temperature of the bar-headed goose breeding grounds dropped from $10^{\circ} \mathrm{C}$ to $-5^{\circ} \mathrm{C}$, and the mean temperature of the wintering site dropped from $12^{\circ} \mathrm{C}$ to $2^{\circ} \mathrm{C}$. The mean temperature of wintering area remained above $0^{\circ} \mathrm{C}$, despite an elevation of nearly 3500 meters. The autumn migration routes of bar-headed geese in the Tibetan Plateau, from breeding grounds to wintering areas, pass through an area with below average temperatures. The mean temperature at Stopover 2 (Figure 3) dropped from $4^{\circ} \mathrm{C}$ to $-6^{\circ} \mathrm{C}$, and the mean temperature at Stopover 3 which correlates closely with Stopover 4 , dropped from $8^{\circ} \mathrm{C}$ to $-8^{\circ} \mathrm{C}$ between August and November.

2.5. Stopover Sites and NDVI Variation. Bar-headed geese seemed to migrate in response to seasonal temperature changes, particularly when reflected in environmental conditions such as variation in green-up (as indicated by the NDVI) within breeding, stopover, and wintering sites. Analysis of inter-annual variation of vegetation and its relationship to climatic change on the Tibetan Plateau with a 21-year NDVI dataset by Zhou et al. [21] showed that vegetation coverage was early in the eastern and southern plateau regions, and that it was later as it moved toward the west and north. On the whole, vegetation growth demonstrated a gradual although oscillatory increase during the period from 19822002. This temporal variation exhibited striking regional differences; an increasing trend was most apparent in the north, 

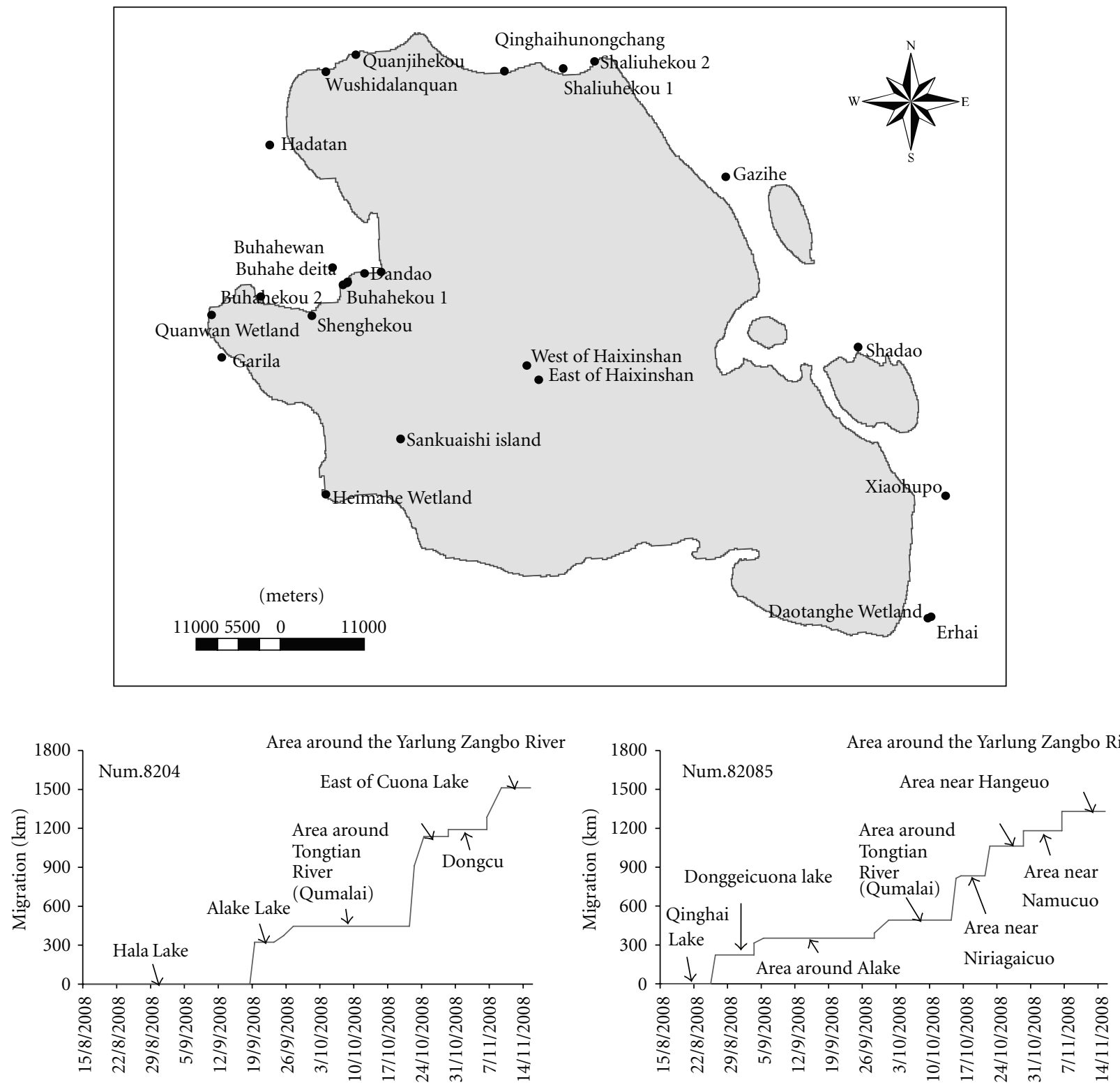

Migration date
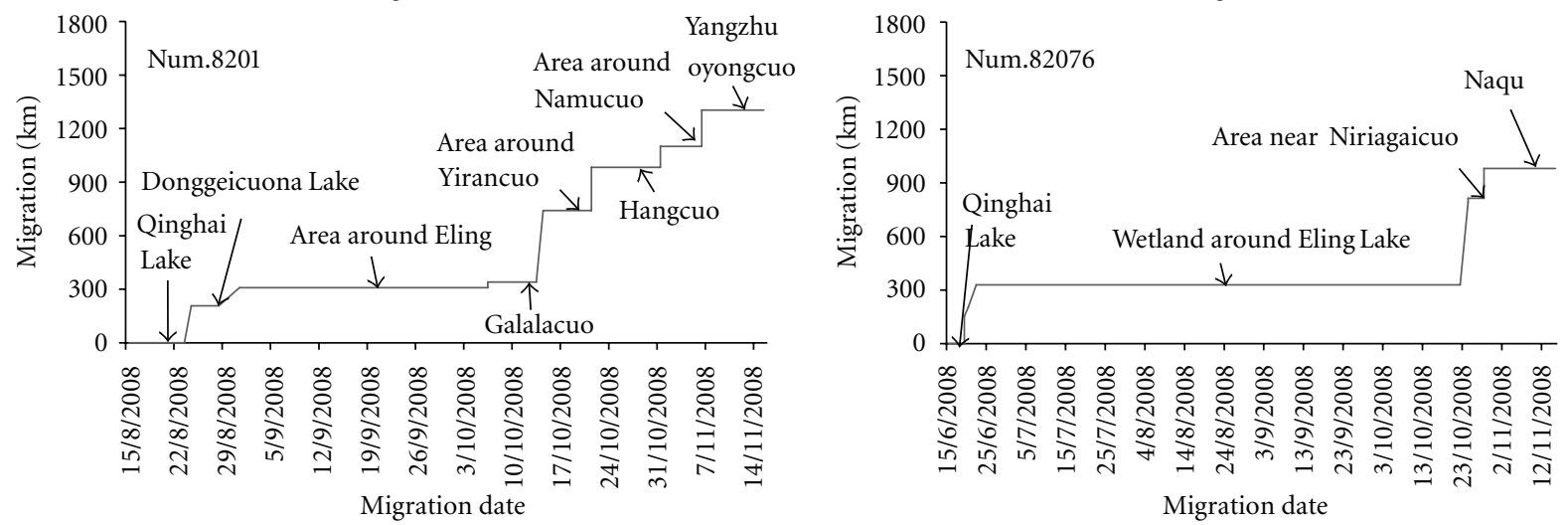

FIGURE 2: Map of primary areas used by bar-headed geese at Qinghai Lake, and distances traveled by date during the autumn migration in China. 

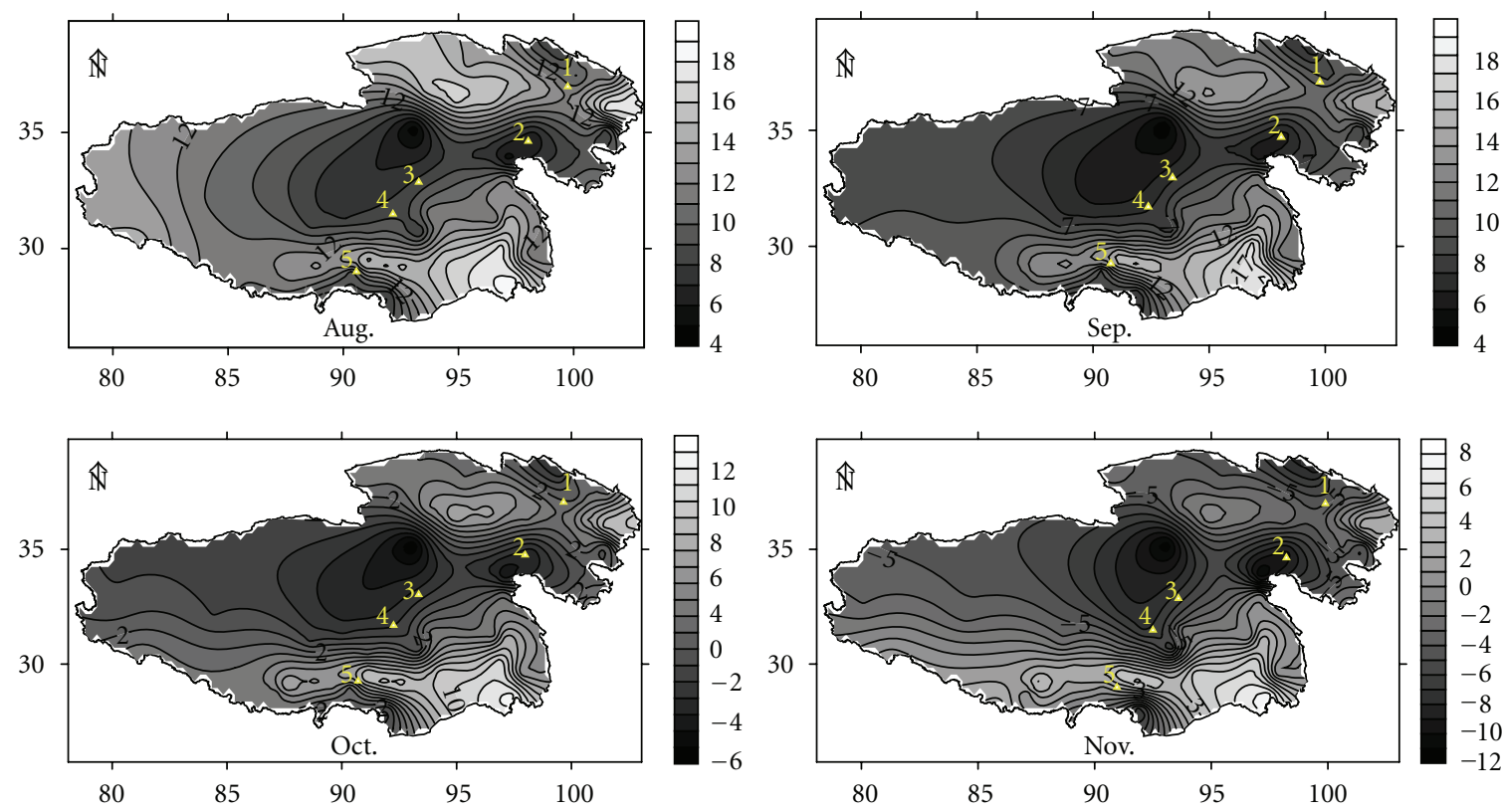

FIGURE 3: Relationship between stopover sites and monthly mean surface temperature $\left({ }^{\circ} \mathrm{C}\right)$, where areas include (1) Qinghai Lake; (2) Eling Lake; (3) Niriagaicuo; (4) Naqu; (5) Yarlung Zangbo River. The horizontal axis denotes longitude in degrees while the vertical axis indicates longitude. The graduated shading represents temperature isotherms from lower (darker shading) to higher (lighter shading) temperature.

west, south, and southeast, whereas a decreasing trend was present along the southern plateau boundary and in the eastcentral region.

Monthly NDVI graphics were overlaid onto 4 typical migratory routes in 2008 of representative bar-headed geese with the NDVI data (MOD13A3) (Figure 4). The value of NDVI is stand for the type of surface. Negative values of NDVI (values approaching -1) correspond to water. Values close to zero $(-0.1$ to 0.1$)$ generally correspond to barren areas of rock, sand, or snow. Lastly, low, positive values represent shrub and grassland (approximately 0.2 to 0.4 ), while high values indicate temperate and tropical rainforests (values approaching 1).

\section{Results}

By analyzing the tracking data for 11 bar-headed geese captured at Qinghai Lake, it was determined that 7 of the geese bred and moulted in Qinghai Lake, then traveled by way of Donggeicuona Lake, Alake Lake, Qumalai, and Hangcuo, and wintered in the watersheds of the Yarlung Zangbo and Nianchu rivers in Tibet (Figure 1). Two geese went to Qinghai Lake for a short stay, and then bred and moulted in the wetlands near Hala Lake, traveling by way of Alake Lake and Qumalai, and wintered in the watershed of the Yarlung Zangbo River in Tibet. One goose bred and moulted in Qinghai Lake, then traveled by way of Donggeicuona Lake, Eling Lake, and Hangcuo with a short stay in Tibet before flying over the Himalayan mountains to winter in India; one bar-headed goose bred in Qinghai Lake and moulted in either Eling Lake or Zhaling Lake and migrated to Naqu for wintering (its signal was lost after November 25th, but it was found there again the following year). These results show that all the bar-headed geese migrated from breeding grounds to wintering grounds along the same general route, but neither the migration times, arrival times, stopover sites, nor duration of stopovers were the same for all geese.

In general, these geese traveled distances between 1300 and $1500 \mathrm{~km}$ from breeding to wintering areas, stopped at three to six sites and took from 73 to 83 days to travel this distance in the autumn of 2008. Stopover duration and migratory routes for 4 representative birds were plotted from the satellite-tracking data (Figure 1). Some stopover locations were common to the geese, but others such as Donggeicuona Lake and Eling Lake were not used by all geese, and the duration of their stopover varied. Bar-headed geese were located in wetland, lakes, and moving water habitats, and their stopover duration was closely related to the type of habitat with longer duration that was potentially associated with plentiful food and refuge from predators.

According to the presetting site and tracking investigation by the members of Qinghai Lake Joint Research Institute in August 2008, 13 migratory stopovers of bar-headed geese were found in the Tibetan Plateau-South Mountain near Qinghai Lake, Doucuo Lake, Donggeicuona Lake, Hangheyan, Eling Lake, Zhaling Lake, Niutou Mountain, Xingxinghai, Guoermacuo, Longbaotan, the Lhasa Valaley, and Lalu wetlands. The habitat types of stopovers are mainly lake, marshland, and other shallow waters, but some are farmlands. Vegetation types are those associated with temperate steppes, swamp meadows, deserts, saline meadows, alpine meadows, shrub land, and abandoned farmland that provide adequate grasses for foraging.

Overlaying major bar-headed goose breeding and wintering sites and migratory stopovers onto the Figure 3 diagram, 


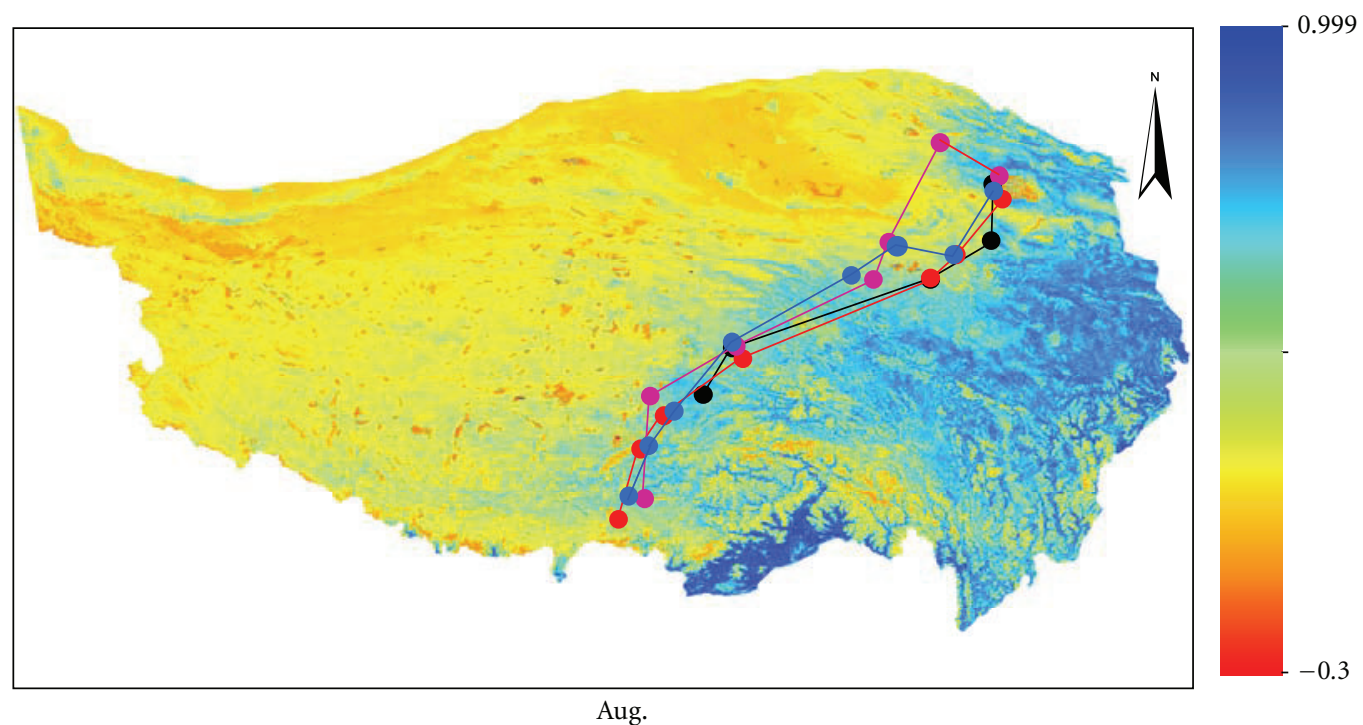

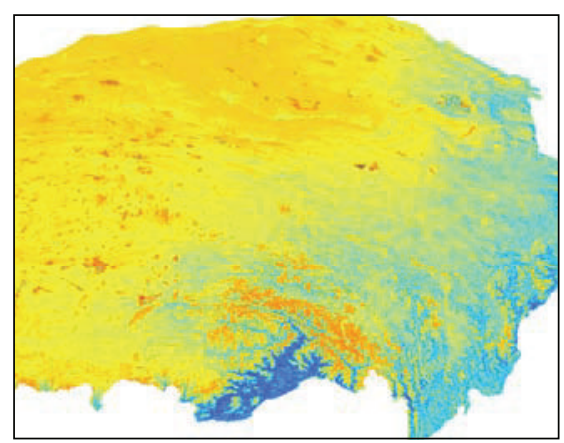

May.

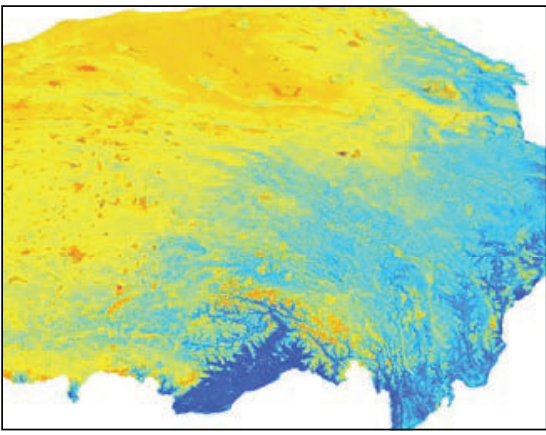

Jun.

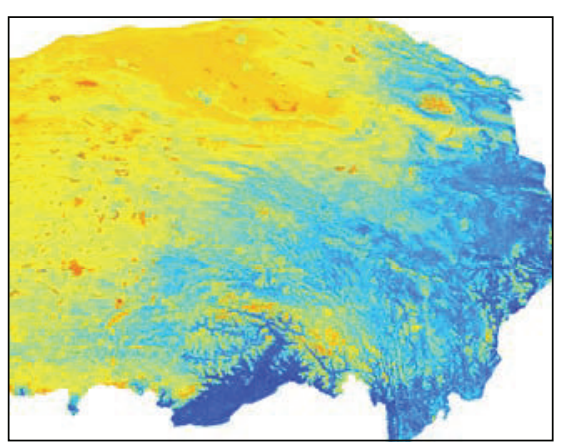

Jul.

FIGURE 4: Variation in the monthly vegetation index (NDVI) at migratory stopovers for bar-headed geese during the autumn migration. Colored lines indicate the north-to-south migratory routes of four representative bar-headed geese.

it was found that from August to November (i.e., during the autumn migratory season), the mean temperature of the bar-headed goose breeding grounds decreased from $10^{\circ} \mathrm{C}$ to $-5^{\circ} \mathrm{C}$, and the mean temperature of the wintering site dropped from $12^{\circ} \mathrm{C}$ to $2^{\circ} \mathrm{C}$. The temperature of wintering area remained above $0^{\circ} \mathrm{C}$, despite an elevation of nearly 3500 meters. The autumn migration routes of bar-headed geese in the Tibetan Plateau, from breeding grounds to wintering areas, pass through an area with below average temperatures. The mean temperature at Stopover 2 (Figure 3) dropped from $4^{\circ} \mathrm{C}$ to $-6^{\circ} \mathrm{C}$, and the mean temperature at Stopover 3 which correlates closely with Stopover 4, dropped from $8^{\circ} \mathrm{C}$ to $-8^{\circ} \mathrm{C}$ between August and November.

Vegetation coverage gradually increased (Figure 4) and the increasing trend was greatest in the east and south and less in the west and the north, especially between May and August. Vegetation coverage was greatest in the eastern and southern plateau regions and decreased toward the west and north. An increasing trend was apparent moving from east to west. In general, migratory stopover sites were located where the vegetation cover was greatest and were distributed at the transition zone between the least and most vegetative cover. Migration along the transition zone is apparent in
August (Figure 4) where NDVI $=0.5$ at the stopover sites. In October, the vegetation starts to wilt, and by November the growth is almost gone (Figure 5).

\section{Discussion}

The timing and movements of bar-headed goose during the autumn migration were related to climatic conditions. Climate changes on the Tibetan Plateau transition gradually from north to south in the autumn when bar-headed geese start to migrate southward to their wintering grounds. From August to November, the mean temperature of bar-headed goose breeding sites at Qinghai Lake dropped from $10^{\circ} \mathrm{C}$ to $-5^{\circ} \mathrm{C}$, and the mean temperature at the wintering site dropped from $12^{\circ} \mathrm{C}$ to $2^{\circ} \mathrm{C}$. Analysis of the temperature changes at stopovers during the autumn migratory season showed that although the temperature of major stopovers gradually decreased during this migratory period, the temperature of all of the stopovers remained above $0^{\circ} \mathrm{C}$. For example, in September, the mean temperature at Stopover 2 was about $5^{\circ} \mathrm{C}$, and in October, the mean temperature at Stopovers 3 and 4 was $1{ }^{\circ} \mathrm{C}$ (Figure 3 ). Seasonal temperature change may be important factors dictating the timing of 

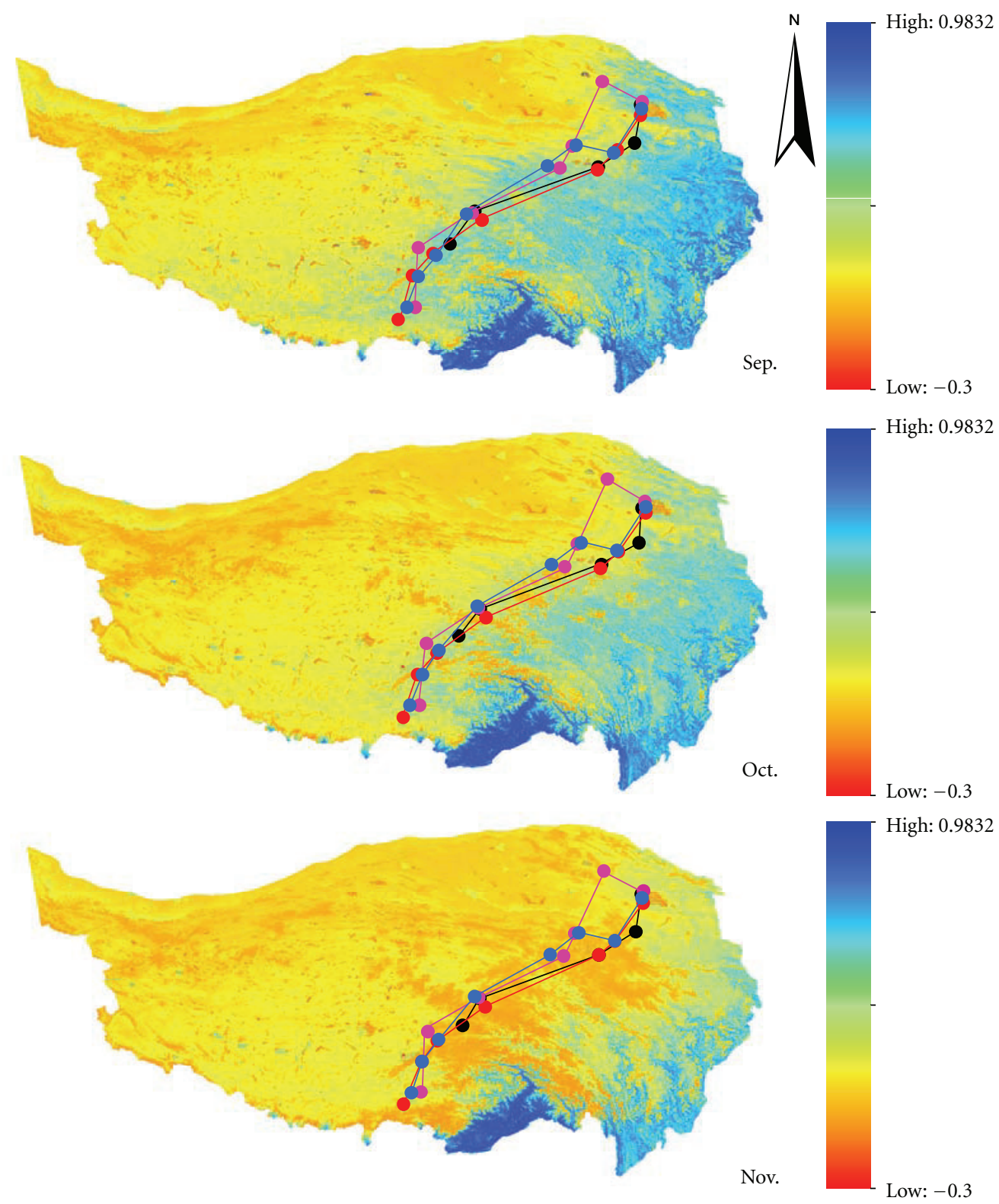

Figure 5: Vegetation index (NDVI) variation on the Tibetan Plateau during the autumn migration in 2008. Colored lines indicate 4 representative bar-headed goose migration tracks during their north-to-south autumn migration.

the bar-headed goose migration, and the geese seemed to use areas that remained above $0^{\circ} \mathrm{C}$.

The migration routes and the duration of stay at breeding, wintering, and stopover sites for bar-headed geese were related to vegetation coverage on the ground, which was expressed as the value of the NDVI. The migration route used by bar-headed geese may be related to the unique vegetation distribution inferred from vegetation coverage in summer. Vegetation coverage is greatest in the eastern and southern plateau regions and decreases toward the west and the north. Vegetation growth is highest on the Tibetan Plateau in July, August, and September with the most extensive coverage in August (Figure 4). Migratory stopovers tended to be located along the transition zone where vegetation coverage is predictably better during the vigorous growth season, but where, in the autumn, the NDVI in the transition zone drops to its minimum (Figure 5). The majority of the migratory stopovers of bar-headed geese are also located in wetland and marshland habitat.

We found individual variation in migration patterns with regard to distance, direction, duration, and even wintering destination. These differences could be related to the condition of the individual, the availability of suitable habitats along the migration route, the migratory date, and the local climatic conditions such as wind direction during the migration.

Our study demonstrates that bar-headed geese can cross the Tibetan Plateau during their autumn migration which 
has an elevation of 3000 to $5000 \mathrm{~m}$ above sea level. The fact that geese migrate in this oxygen-deficient environment, especially considering the length of the migratory routes, suggests they have adaptations for flight at high altitude conditions [22-25]. In this study, only one of 11 barheaded geese flew over the Himalayan Mountains which may indicate that individuals breeding at Qinghai Lake primarily winter within China. Migration strategies involving flight over longer distances have been documented including barheaded geese that breed in Mongolia and spend winter in Peninsular India [7].

\section{Acknowledgments}

This work is supported by the Incubation Foundation for Special Disciplines of NSFC (National Science Foundation of China) (Grant no. J0630966), the Disease Monitoring and Risk Assessment of Important Wild Birds in Qinghai lake region of E-Science Application of Research on Resources for Special Project of Informatization of CAS (Chinese Academy of Sciences) in "the Eleventh Five-Year Plan" (Grant no. INFO-115-D02); the U.S. Geological Survey (Patuxent Wildlife Research Center, Western Ecological Research Center, Alaska Science Center, and Avian Influenza Program), the United Nations Food and Agriculture Organization, Animal Production and Health Division, EMPRES Wildlife Unit, National Science Foundation Small Grants for Exploratory Research (no. 0713027), and the Chinese Academy of Sciences (no. 2007FY210700, INFO-115-D02, KSCX2-YW-N-063, and 2005CB523007). The authors are grateful to the Qinghai Lake National Nature Reserve staff, Qinghai Forestry Bureau (S. Li), Chinese Academy of Sciences (X. Hu, L. Hu, N. Kong, Z. Luo) provided helpful comments to strengthen earlier versions of this paper. The use of trade, product, or firm names in this publication is for descriptive purposes only and does not imply endorsement by the US Government.

\section{References}

[1] D. J. Prosser, J. Y. Takekawa, S. H. Newman et al., "Satellitemarked waterfowl reveal migratory connection between H5N1 outbreak areas in China and Mongolia," Ibis, vol. 151, no. 3, pp. 568-576, 2009.

[2] X. H. Zhang and H. F. Zhang, "Discussion on the relation between birds' migration and poultry flu," Journal of Taiyuan Teachers College, vol. 4, no. 4, pp. 81-84, 2005.

[3] D. J. Prosser, P. Cui, J. Y. Takekawa, M. Tang, Y. Hou et al., "Wild bird migration across the Qinghai-Tibetan Plateau: a potential transmission route for highly pathogenic $\mathrm{H} 5 \mathrm{~N} 1$," PLoS One, vol. 6, Article ID e17622, 2011.

[4] H. Chen, G. J. D. Smith, S. Y. Zhang et al., "Avian flu: H5N1 virus outbreak in migratory waterfowl," Nature, vol. 436, no. 7048, pp. 191-192, 2005.

[5] H. Inge, S. Dirk, and B. Gerhard, "High-altitude respiration of birds. The primary structures of the $\alpha \mathrm{D}$-chains of the barheaded goose (Anser indicus), the greylag goose (Anser anser) and the Canada Goose (Branta canadensis)," Biological Chemistry Hoppe-Seyler, vol. 367, no. 2, pp. 591-599, 1986.
[6] Y. L. Song, Z. M. Canjue, and M. A. Bishop, "Bar-headed geese Anser indicus wintering population number and distribution in south-central Tibet Yarlung Zangbo River region," Chinese Journal of Zoology, vol. 29, no. 2, pp. 27-30, 1994.

[7] J. Y. Takekawa, S. R. Heath, D. C. Douglas et al., "Geographic variation in Bar-headed Geese Anser indicus: connectivity of wintering areas and breeding grounds across a broad front," Wildfowl, vol. 59, pp. 100-125, 2009.

[8] S. Javed, J.Y. Takekawa, Douglas et al., "Tracking the spring migration of a bar-headed goose (Anser indicus) across the Himalaya with satellite telemetry," Global Environmental Research, vol. 2, pp. 195-205, 2000.

[9] S. Javed, H. Higuchi, M. Nagendran, and J. Y. Takekawa, "Satellite telemetry and wildlife studies in India: advantages, options and challenges," Current Science, vol. 85, no. 10, pp. 1439-1443, 2003.

[10] H. Q. Wu, X. J. Yang, J. X. Yang et al., "Review of satellite tracking in bird migratory studies," Zoology Research, vol. 29, no. 3, pp. 346-352, 2008.

[11] G. Z. Chu, Y. Q. Hou, G. G. Zhang et al., "Satellite tracking of the migratory routes of the waterbirds breeding in Qinghailake," Chinese Journal of Nature, vol. 30, no. 2, pp. 84-89, 2007.

[12] D. P. Liu, G. G. Zhang, H. X. Jiang et al., "Movement and habitat utilization of breeding Bar-headed Goose and the relationship with humans in Qinghai Lake," Acta Ecologica Sinica, vol. 28, no. 11, pp. 5201-5208, 2008.

[13] G. G. Zhang, D. P. Liu, and H. X. Jiang, "Movement of four breeding waterbirds at Qinghai lake," Biodiversity Science, vol. 16, no. 3, pp. 279-287, 2008.

[14] M. J. Tang, Y. C. Zhou, P. Cui et al., "Discovery of migration habitats and routes of wild bird species by clustering and association analysis. Advanced data mining and applications," in Proceedings of the 5th International Conference on Advanced Data Mining and Applications (ADMA 2009), pp. 288-301, Beijing, China, August 2009.

[15] M. A. Bishop, S. Yanling, C. Zhouma, and G. Binyuan, "Barheaded Geese Anser indicus wintering in south-central Tibet," Wildfowl, vol. 48, pp. 118-126, 1997.

[16] H. Higuchi, Y. Shibaev, J. Minton et al., "Satellite tracking of the migration of the red-crowned crane Grus japonensis," Ecological Research, vol. 13, no. 3, pp. 273-282, 1998.

[17] H. Higuchi, H. J. Shiu, H. Nakamura et al., "Migration of Honey-buzzards Pernisa pivorus based on satellite tracking," Ornithological Science, vol. 4, pp. 109-115, 2005.

[18] P. Cui, Y. Hou, M. Tang et al., "Movement patterns of Barheaded Geese Anser indicus during breeding and postbreeding periods at Qinghai Lake, China," Journal of Ornithology, vol. 152, no. 1, pp. 83-92, 2011.

[19] C. R. Ely, K. S. Bollinger, R. V. Densmore et al., "Reproductive strategies of northern geese: why wait?" Auk, vol. 124, no. 2, pp. 594-605, 2007.

[20] Y. F. Yang, H. Jiang, F. J. Niu et al., "The space-time variation analysis of air temperature over the Qinghai-Xizang plateau in warm and cold seasons," Plateau Meteorology, vol. 26, no. 3, pp. 496-502, 2007.

[21] D. W. Zhou, G. Z. Fan, R. H. Huang, Z. Fang, Y. Liu, and H. Li, "Interannual variability of the normalized difference vegetation index on the Tibetan plateau and its relationship with climate change," Advances in Atmospheric Sciences, vol. 24, no. 3, pp. 474-484, 2007.

[22] W. J. Fang, Z. Q. Hua, Y. H. Liang et al., "Study on resonance roman spectra of stock solutions of bar-headed goose hemoglobin for crystal growth under space and earth 
conditions," Chinese Journal of Light Scattering, vol. 16, no. 2, pp. 107-109, 2004.

[23] L. A. Hawkes, S. Balanchandran, N. Batbayar et al., "The trans-Himalayan flights of bar-headed geese (Anser indicus)," Proceedings of the National Academy of Sciences of the United States, vol. 108, pp. 9516-9519, 2011.

[24] Y. Liang, Z. Hua, X. Liang, Q. Xu, and G. Lu, "The crystal structure of bar-headed goose hemoglobin in deoxy form: the allosteric mechanism of a hemoglobin species with high oxygen affinity," Journal of Molecular Biology, vol. 313, no. 1, pp. 123-137, 2001.

[25] G. R. Scott and W. K. Milsom, "Control of breathing and adaptation to high altitude in the bar-headed goose," The American Journal of Physiology, vol. 293, no. 1, pp. R379-R391, 2007. 

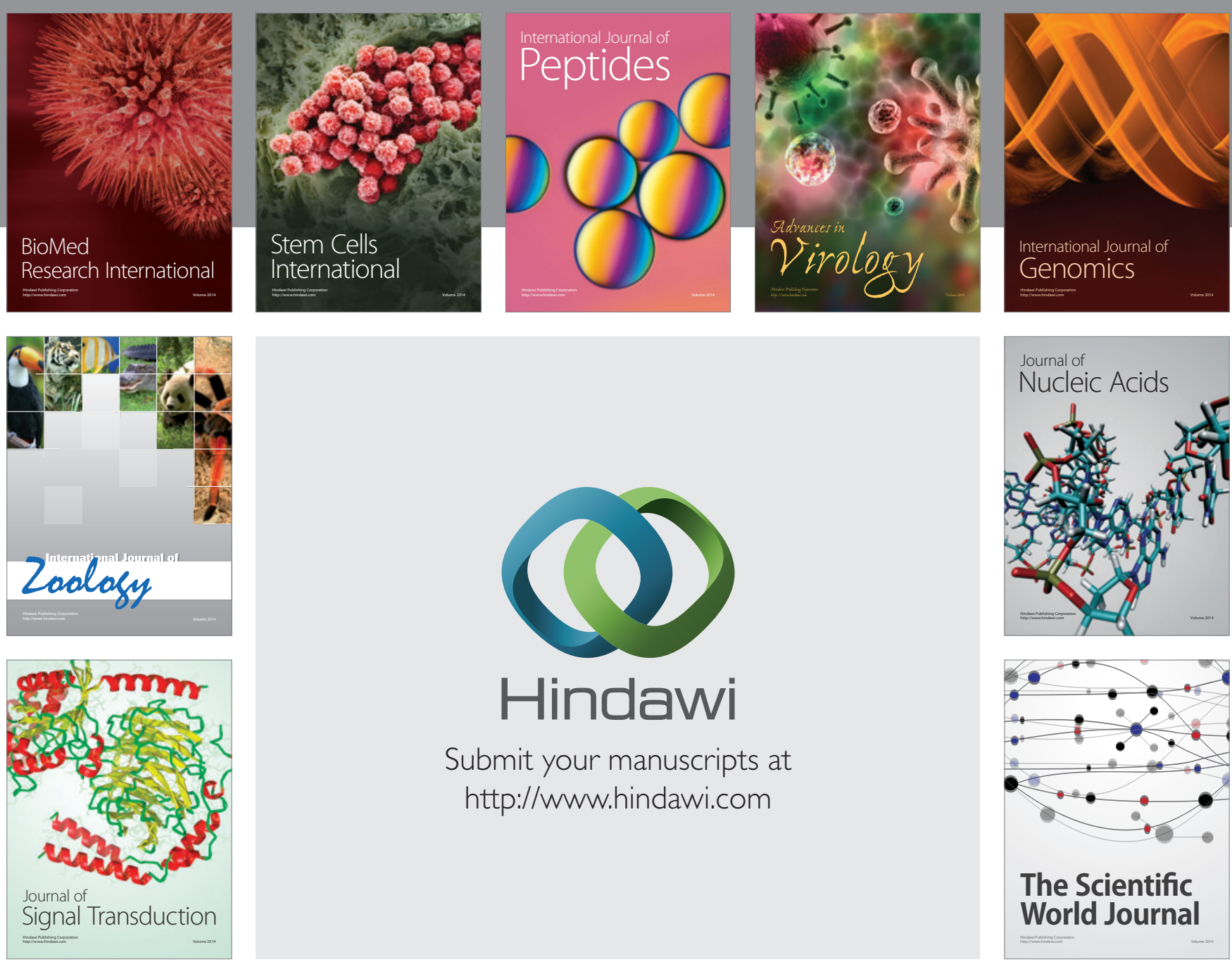

Submit your manuscripts at

http://www.hindawi.com
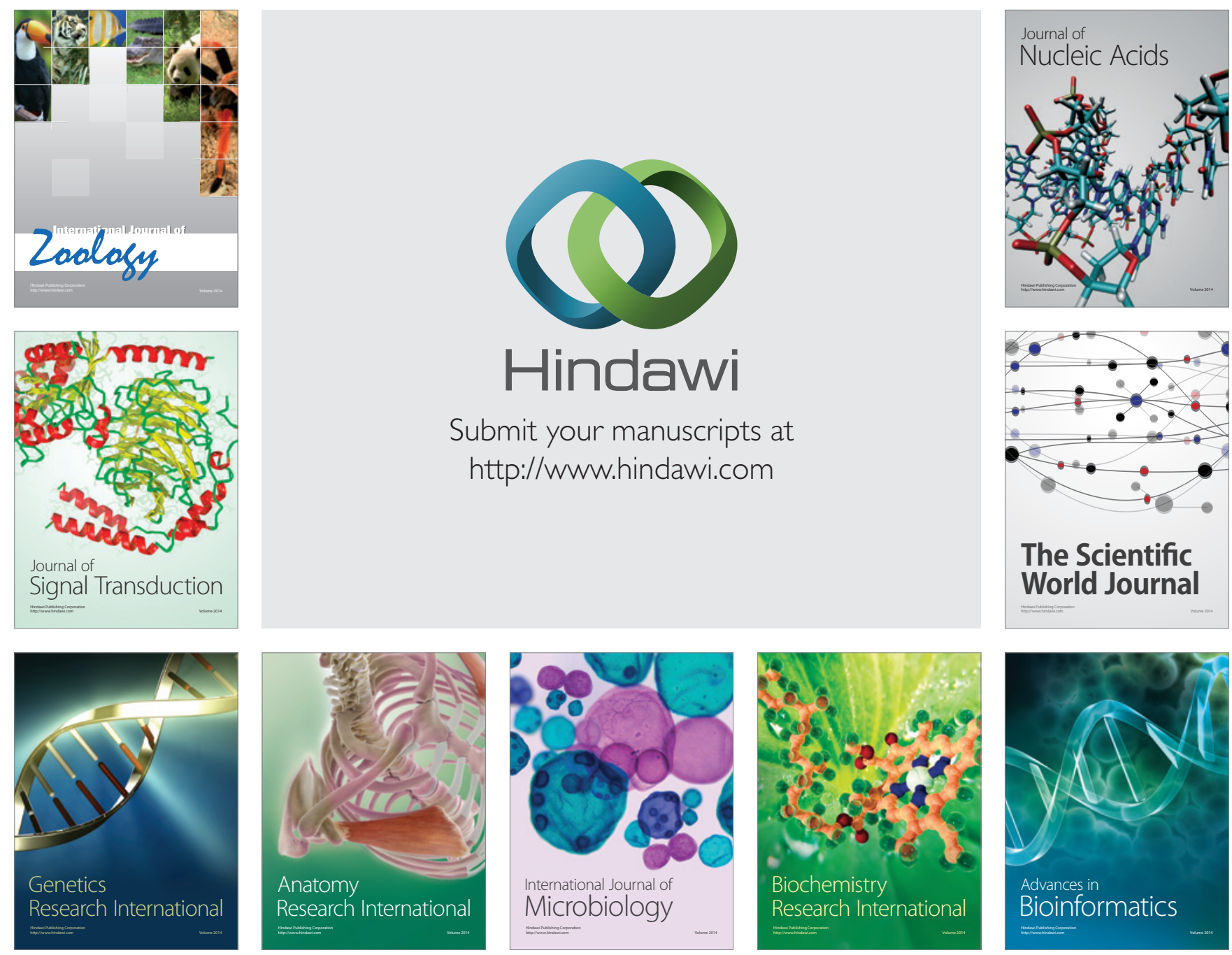

The Scientific World Journal
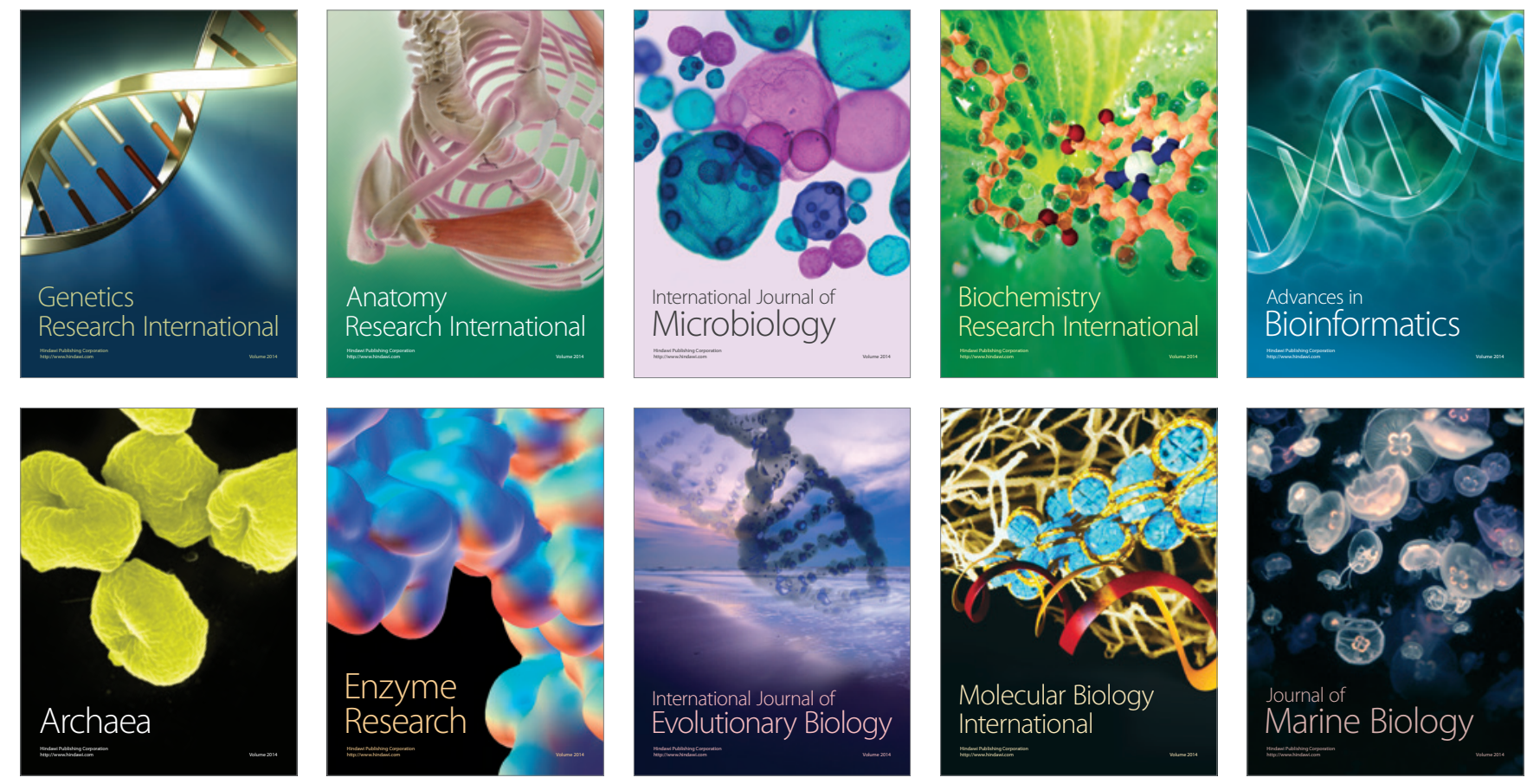